\title{
Embryonic diapause modulates ovarian follicular dynamics and oocyte quality in the European roe deer (Capreolus capreolus)
}

\author{
SM Bernal-Ulloa ${ }^{1}$, JT Bick ${ }^{1}$, VA van der Weijden ${ }^{1}$, AB Rüegg ${ }^{1}$, B Drews ${ }^{1}$, MP \\ Kowalewski ${ }^{2}$, S Bauersachs ${ }^{3}$, SE Ulbrich ${ }^{1}$ \\ ${ }^{1}$ Institute of Agricultural Sciences, ETH Zurich, Switzerland \\ ${ }^{2}$ Institute of Veterinary Anatomy, Vetsuisse Faculty, University of Zurich, Zurich, \\ Switzerland \\ ${ }^{3}$ Genetics and Functional Genomics, Clinic of Reproductive Medicine, Department for Farm \\ Animals, University of Zurich, Zurich, Switzerland \\ Corresponding author email: $\underline{\text { seu@ethz.ch }}$
}

\begin{abstract}
The phenomenon of embryonic diapause has been reported to possibly affect ovarian follicular development. The aim of the current study was to identify the impact of the embryonic diapause period on follicle number and oocyte quality in the European roe deer (Capreolus capreolus). In this species, the embryo undergoes five months of developmental delay. We have determined the antral follicle count (AFC), oocyte morphological quality, oocyte meiotic resumption capacity and the transcriptome profile in immature (GV) and in vitro matured (MII) oocytes obtained during embryonic diapause and after embryo reactivation. A drop in AFC, number of oocytes suitable for in vitro maturation and oocytes reaching the MII stage was observed after embryonic reactivation. A large impact of the diapause period was evident when MII oocytes were compared against GV oocytes using an RNA-seq approach. A total of 1028 genes significantly differed between MII and GV oocytes during diapause and 1795 genes after reactivation. These genes included PDE3A and SOD2, known for being involved in oocyte meiotic arrest and oxidative stress. In addition, tumour-related genes included NDRG3, NCSTN and UGDH, which have been associated with cell proliferation, migration and metabolism, were found. Comparing diapause versus reactivation, differential transcript abundance in both GV and MII oocytes was observed (44 and 32 differentially expressed genes, respectively). Our results suggest that the embryonic diapause and reactivation periods modulate follicular dynamics, influencing the oocyte towards lower quality after reactivation. This is may be related to increased apoptosis, abnormal mitochondria function/structure and metabolic dysfunction in the maturing oocyte.
\end{abstract}

\section{Introduction}

Embryonic developmental delay, termed embryonic diapause, occurs in more than 130 mammalian species. However, this process is still enigmatic and not fully understood to date $[1,2]$. In the European Roe Deer (Capreolus capreolus), the only known ungulate that exhibits this phenomenon, the rut starts at the end of July/beginning of August. The female roe deer is considered a seasonally monoestrus breeder [3], with an estrus duration of approximately 36h [4]. The start of the breeding season and further ovulation are modulated by melatonin. In animals receiving melatonin implants in mid-April, a sharp decreased in prolactin and an advancement of the ovulatory period by 72 days, indicated by the increment of blood progesterone (P4) concentrations, has been reported [5]. 
Furthermore, the exposure to artificial long days from the summer solstice delayed ovulation by 46 days [5]. In the absence of a male, peripheral P4 concentrations rise after spontaneous ovulation and corpus luteum $(\mathrm{CL})$ formation occurs. Thereupon, P4 levels are maintain until March [6, 7]. Furthermore, oxytocin (OXT) has been found in the CL during the breeding season and the CL was able to secrete OXT in response to the administration of the PGF2 $\alpha$ analogue cloprostenol [3]. However, administration of OXT did not stimulate uterine secretion of PGF2 $\alpha$ [3], although OXT receptors have been found in the uterus during the breeding season and diapause, thus differing from other ruminants [3]. After fertilization, the roe deer embryos develop to the blastocyst stage and hatch from the zona pellucida. Afterwards, blastocysts enter a phase of developmental delay or obligate embryonic diapause [8]. Embryonic reactivation and implantation only take place at the end of December /beginning of January [8]. Peripheral plasma/serum oestradiol concentrations remain low during diapause. A following increase after embryo elongation has been reported [9]. Furthermore, basal prolactin (PRL) concentrations during diapause displaying a substantial increase after implantation have been observed. In contrast, peripheral and luteal P4 concentrations remain constant throughout diapause, elongation and implantation [9]. Additional reports have suggested a rise in P4 levels between January and March prior to a reported decrease in March in pregnant does [3]. Furthermore, no differences in CL mass in does carrying a blastocyst and non-pregnant does have been reported [3]. Up to date, most efforts on the field of embryonic diapause in mammals have focused on studying the maternal endocrinology, embryonic morphology, the uterine environment as well as their interaction during the developmental delay and reactivation processes. Little is known about the female gonads and oocyte characteristics in roe deer. Interestingly, some of the potential diapause regulatory factors described in mice, mink and invertebrates (reviewed by [2]) are also involved in follicle/oocyte mitotic/meiotic arrest maintenance and activation. These comprise the mammalian target of rapamycin $(m T O R)[10,11]$, the MYC proto-oncogene, bHLH transcription factor (MYC) [12] and the forkhead box class O family member 3 (FOXO3) $[13,14]$. Additionally, the same factors have also been related to the aging process (reviewed by [15]).

Recently, a decrease in ovarian follicle number following embryonic reactivation was reported in the roe deer [16]. A potential impact of diapause on follicular physiology was likewise suggested [16]. We hypothesise that diapause could play a role in modifying the ovarian activity and therefore oocyte quality. Hence, we studied the ovarian characteristics and oocyte quality during the embryonic diapause and reactivation period in the roe deer by combining morphological observations, cellular and transcriptomics analyses to identify whether these developmental stages influence the follicle population, the oocyte mRNA abundance profiles and the oocyte capacity to resume meiosis.

\section{Materials and methods}

All reagents of analytical grade were supplied by Sigma-Aldrich Co. (St. Louis, USA) unless otherwise stated. Sample collection did not require ethical approval, since it was performed during regular hunts and none of the animals was culled for scientific purposes. In the present study, the status of the retrieved ovaries and their respective oocytes was allocated to one of two different periods, according to the corresponding embryo stage. The periods were determined as "Diapause (D)" (embryo in embryonic diapause characterized by a round morphology) and "Reactivation (R)" (embryo elongated or implanted). To determine the reproductive status of the females and the embryonic developmental stage, the uterus horns were either flushed or opened by cutting (when implantation was observed) for embryo retrieval. Since non-pregnant does from hunted animals cannot be confirmed, females in which an embryo was not found were excluded. Therefore, only does with a known embryonic developmental stage were included in the analyses. 


\section{Roe deer ovarian characteristics}

Roe deer ovaries were retrieved in northern Switzerland and southern Germany between October 2016 - January 2017 and October 2017 - January 2018. A total of 141 hunted animals were considered for the analyses. The length and width of each ovary was determined to estimate the ovarian surface area $\left(\mathrm{mm}^{2}\right)$ using the formula for an ellipse (length $x$ width $\left.x \pi / 4\right)$ [17]. Follicles visible on the ovary surface were counted and classified according to their size in three different groups: small $<1 \mathrm{~mm}$, medium 1.1-4.9 $\mathrm{mm}$ and big $>5 \mathrm{~mm}$. Corpora lutea $(\mathrm{CL})$ were documented and included for ovary classification, namely no presence of a $\mathrm{CL}(0 \mathrm{CL})$, one $\mathrm{CL}$ present $(1 \mathrm{CL})$, or two or more $\mathrm{CL}$ present ( $\geq 2 \mathrm{CL}$ ), respectively.

\section{Roe deer oocyte retrieval}

After ovarian morphological features were documented, both ovaries from the same female were sliced in BO-OPU medium (IVF Bioscience, IVF Limited T/A IVF Bioscience, Bickland Industrial Park, Falmouth, Cornwall, United Kingdom) at $35^{\circ} \mathrm{C}$. Oocytes were collected and classified in BO-Wash medium (IVF Bioscience) according to six (I-VI) morphological categories [18]: Category I: Oocytes with more than four layers of compact cumulus cells and a regular cytoplasm. Category II: Oocytes with three to four layers of compact cumulus cells, regular cytoplasm or lightly granulated. Category III: Oocytes with one to two layers of cumulus of corona radiata, cytoplasm with irregular appearance, such as dark areas. Category IV: Denuded oocytes. Category V: Oocytes with expanded cumulus. Category VI: Degenerated oocytes. Oocytes classification was performed randomly for 15 animals for each embryo developmental group/phase.

\section{In vitro oocyte maturation (IVM)}

After classification, roe deer oocytes were washed in $3 \mathrm{ml}$ maturation medium (BO-HEPES IVM, IVF Bioscience). Thereafter, oocytes were transported to the lab at $38.5^{\circ} \mathrm{C}$ in $1 \mathrm{ml}$ glass tubes containing $500 \mu \mathrm{L}$ of the maturation medium and a maximum of 20 oocytes per tube. Oocytes were cultured for $22-26 \mathrm{~h}$ at $38.5^{\circ} \mathrm{C}$ and only oocytes from categories I, II and III were used for IVM.

\section{Processing of immature and in vitro mature oocytes for analyses}

Immature (GV, germinal vesicle stage) and in vitro matured (MII, metaphase II stage) roe deer oocytes were denuded by incubation in Dulbecco's phosphate buffer saline (PBS, AppliChem $\mathrm{GmbH}$, Darmstadt, Germany), supplemented with $0.1 \%$ hyaluronidase and $1 \mathrm{mg} / \mathrm{ml}$ BSA (Fraction V) for $3 \mathrm{~min}$ at $38.5^{\circ}$ and after vortexed for $1 \mathrm{~min}$ at $1400 \mathrm{rpm}$. The remaining cumulus cells were removed by gentle pipetting. Maturation was confirmed by the presence of the first polar body in the perivitelline space (MII). Single denuded immature and matured oocytes were snap frozen at $80^{\circ} \mathrm{C}$, in PBS enriched with $0.1 \%$ polyvinyl alcohol (PVA) (PBS-PVA solution) for further analysis.

\section{Evaluation of oocyte maturation}

After maturation, oocytes were denuded as described above, fixed in PBS-PVA solution containing $10 \%$ paraformaldehyde, and maintained at $4^{\circ} \mathrm{C}$ until evaluation. Prior to analysis, oocytes were washed twice in PBS-PVA and stained with a PBS-PVA solution containing $0.2 \mathrm{mg} / \mathrm{ml}$ propidium iodide and $0.4 \%$ triton for five minutes. For nuclear evaluation, oocytes were mounted on glass slides and covered with a cover slip. Oocyte evaluation was immediately performed using a fluorescence microscope (Axioplan 2, Carl Zeiss AG, Oberkochen, Germany) at 400× magnification. The number of oocytes at germinal vesicle (GV), germinal vesicle breakdown (GVBD), metaphase I (MI), anaphase I (AI), telophase I (TI), metaphase II (MII) and non-evaluable stages (NE) was determined. Oocyte nuclear stage was evaluated in 11 and 8 randomly selected animals for the diapause and reactivation periods, respectively. 


\section{Histology of the ovary}

Ovaries from five randomly selected animals in each group ( $D$ and $R$ ) were cut at middle of the sagittal plane in two halves and fixed using 10\% formalin for 24 hours. Thereafter, ovaries were washed in PBS for seven days (PBS was changed daily). Subsequently, samples were dehydrated in graded ethanol series (30\%, 50\% and 70\%, $24 \mathrm{~h}$ each) and finally embedded in paraffin. For histological analyses, ovarian slices were cut at a thickness of 2-3 $\mu \mathrm{m}$ on a rotary microtome in the sagittal plane, and processed in routine hematoxylin and eosin staining.

\section{Oocyte mRNA library preparation}

Pools of oocytes were processed using the Smart-seq2 single cell protocol for full-length cDNA and library preparation as previously described [19]. Single oocytes were grouped in two pools of 10 immature and mature oocytes for both, diapause and reactivation groups, for the analyses (at least four donors/pool, eight libraries in total). Lysis buffer containing free dNTPs and tailed oligo-dT oligonucleotides (30-nt-poly-dT stretch and 25-nt universal 5 'anchor sequence) was added to each pool of oocytes. Afterwards, reverse transcription (RT) was performed at $42^{\circ} \mathrm{C}$ for $90 \mathrm{~min}$, followed by $50^{\circ} \mathrm{C}$ for $2 \mathrm{~min}$. Thereafter, temperature was lowered to $42^{\circ} \mathrm{C}$ for $2 \mathrm{~min}$. This cycle was repeated ten times. Template switching oligos were added to the RT. After RT, 18 cycles preamplification were performed using KAPA HiFi HotStart Ready mix (KAPA Biosystems, Wilmington, Massachusetts, USA) and IS PCR primers. High Sensitivity Bioanalyzer chip (Agilent, Santa Clara, California, USA) was used to assess the quality of the cDNA samples. Tagmentation was carried out using the Illumina Nextera XT DNA sample preparation kit (Illumina Inc, San Diego, California, USA) at $55^{\circ} \mathrm{C}$ for $5 \mathrm{~min}$. Afterwards, 12 cycles PCR amplification were performed, followed by clean up and concentration measurement. Libraries were pooled and sequenced using a HiSeq 4000 platform (Illumina).

\section{Bioinformatics and data analyses}

The obtained sequence reads (FastQ files) were analysed with a locally installed version of Galaxy (https://doi.org/10.1093/nar/gky379). The adapter sequence was clipped with Trim Galore (visited on 2019/04/24) [20] and quality control was done using FastQC. Sequences were mapped with Salmon [21] against a roe deer transcriptome containing 63`935 transcripts (own unpublished data) and annotated against human, bovine and a number of other RefSeq transcripts obtained from NCBI. The read count table was filtered by counts per million (CPM) cut-off to remove transcripts with neglectable read counts and used for statistical analysis with ABSSeq to identify differentially expressed genes (DEG) [22] (parameters: aFold = TRUE and normalization = "qtotal"). Because of some large differences in excounts numbers (normalized count data) between biological replicates from the same oocyte stage and period of time (in both the $D$ and $R$ group), an additional filtering using $<60$ percentage of change and a standard deviation $<13$ was performed. Four different comparisons were performed: i) GV oocytes from the embryo developmental diapause period vs. GV oocytes from the embryo reactivation period (GV_D_Vs_GV_R); ii) MII oocytes from the embryo developmental diapause period vs. MII oocytes from the embryo reactivation period (MII_D_vs_MII_R); iii) GV vs. MII oocytes from the embryo developmental diapause period (GV_D_vs_MII_D); iv) GV vs. MII oocytes from the embryo developmental reactivation period (GV_R_Vs_MII_R). To determine differentially expressed genes (DEG), the adjusted p-value for the analyses was set to $<1 \%$ and a $\log 2$ fold change $(F C)>1 /<1$ was applied for all comparisons as a cut-off. Hierarchical cluster analysis was performed for DEGs using MultiExperiment Viewer (MeV). Venn diagrams were performed using jvenn interactive Venn diagram viewer [23]. The obtained DEG were uploaded to the Ingenuity Pathway Analysis software (IPA: Qiagen, Hilden, Germany) to identify enrichment for Canonical pathways (CP) and Disease and Functions (DF). The level of significance for enrichment in the IPA output is assigned by a $p$-value in the uploaded data set compared with the known molecules in the database for a particular CP and FD entry. Only entries 
with a $p$-value $<0.01$ were included for the analyses. Furthermore, IPA calculates a $z-$ score to infer the activation state: activation/increase or inhibition/decrease. A z-score $>2$ was considered statistically significant.

\section{Statistical analysis of oocyte and ovary data}

Data from ovary size and total and suitable oocyte numbers were evaluated using an analysis of variance model. Follicle numbers and oocyte maturation rates were compared by Kruskal-Wallis test. These statistical tests were performed in R, version 3.6.1 [24] and the significance was set at $P<0.05$.

\section{Results and discussion}

Here, we report for the first time, morphological and molecular oocyte characteristics during the embryonic diapause and reactivation periods in the roe deer. Additionally, we present ovarian characteristics including the follicular growth and ovary size. We have applied next generation transcriptome sequencing to characterize the effects of the embryo developmental stage on the transcriptome relating to GV and MII-staged oocytes during the embryonic diapause and after the reactivation phase.

\section{Ovarian characteristics}

The average surface area of the 282 collected ovaries between October and January did not change between the diapause (D) and embryo reactivation (R) group ( $p>0.05)$ (see Table 1). As expected, the presence of 1 or $2 \mathrm{CL}$ increased the surface area. The total number of follicles and the number of small follicles decreased after reactivation $(p<0.05)$ (see Figure $1 a-b)$. The number of large and medium sized follicles did not differ between $D$ and $R(p>0.05)$ (see Figure $1 b)$. The ovarian histology confirmed the observed findings regarding different populations of follicles, including intact antral and atretic follicles in both $D$ and $R$. Furthermore, in both $D$ and $R$, there were $C L$ not fully and fully integrated in the ovarian structures and covered by the surface epithelium (see Figure 2). Although the number of antral follicles appeared higher in ovaries displaying not fully integrated $\mathrm{CL}$, the number of atretic follicles seemed higher in those ovaries with fully integrated $\mathrm{CL}$, regardless of the experimental group (see Figure 2).

It has been reported that during early pregnancy (between days 6 - 34 post oestrus), bovine ovaries bearing a CL show decreased follicular development as a local effect, meanwhile follicular growth is sustained in the contralateral ovary [25]. However, differences in follicle number in non-pregnant vs. pregnant bovine donors used for ovum pick up have not been reported [26]. In the ewe, a seasonal species, a suppression of antral follicle growth during early gestation remained also restricted to CL-bearing ovaries (days $10-30$ post oestrus [27]) as in the cow. In the red deer, using ultrasound examination, seasonality (anoestrous) has negatively affected the follicle size and longevity. Additionally, little or no luteal activity was observed [28]. In the roe deer using ultrasonography, antral follicular development during diapause in both pregnant and non-pregnant females has been reported [29]. However, the authors did not study the differences in follicular populations. Previous studies from ovarian histological cuts in the roe deer (from August to January hunting season) reported the presence of follicles at all stages of development and atretic follicles present in the majority of the ovaries [30]. Interestingly, mitosis was observed in some follicles, meaning active development [30]. However, the authors did not distinguish diapause from reactivation. In our study, we have observed a drop in antral follicle number in the roe deer potentially related to embryonic reactivation. Interestingly, a comparable pattern in CL number distribution and ovary size in both developmental periods (diapause vs. reactivation) was also evident. Furthermore, previous studies have revealed no differences in the $\mathrm{CL}$ mass in nonpregnant and pregnant roe deer females [3], suggesting that the CL presence influenced the 
follicular growth in a similar manner and that the observed reduction in follicle count might be due to the reactivation period. Although, differences in estradiol-17 $\beta$ (E2) and progesterone (P4) levels have not been found in the roe deer between embryonic diapause and reactivation [16], the possible effects of the CL ovarian integration and its functionality deserves further research.

Table 1. Effects of the embryonic diapause and reactivation on the ovary area in the roe deer.

\begin{tabular}{|c|c|c|c|c|}
\hline \multirow{2}{*}{$\begin{array}{l}\text { Number of CL per } \\
\text { ovary }\end{array}$} & \multicolumn{2}{|c|}{ Diapause } & \multicolumn{2}{|c|}{ Reactivation } \\
\hline & Number of ovaries & Area $\left(\mathrm{mm}^{2}\right)$ & Number of ovaries & Area $\left(\mathrm{mm}^{2}\right)$ \\
\hline $0 \mathrm{CL}$ & 48 & $67.6 \pm 3.7$ & 15 & $59.2 \pm 4.5$ \\
\hline $1 \mathrm{CL}$ & 121 & $76.0 \pm 2.2$ & 37 & $72.8 \pm 4.0$ \\
\hline$\geq 2 \mathrm{CL}$ & 45 & $95.5 \pm 5.2$ & 16 & $89.3 \pm 4.9$ \\
\hline
\end{tabular}

Data are the mean \pm SEM $(p>0.05)$.

\section{Oocyte quality and maturation rates}

Since oocyte quality depends on the follicular environment, we have further analysed the oocyte morphological quality and its ability to resume meiosis. Oocyte quality was evaluated in 15 does at $D$ and $R$. The total number of oocytes did not differ between developmental stages (784 and 711 oocytes from the embryonic diapause and reactivation, respectively, $p>0.05)$. The total number of oocytes per animal was $52.2 \pm 5.0$ vs. $47.4 \pm 8.0$ for $D$ and $R$, respectively ( $p>0.05$ ). When ovary slicing is performed, oocytes are retrieved from follicles differing in size, which can lead to the similar observed oocyte numbers. The total average number of oocytes suitable for IVM (Qualities I-III) per animal was $27.7 \pm 3.0$ for $D$ and $12.8 \pm 2.0$ for $R(p<0.05)$. Maturation rates were randomly analysed in oocytes from 11 and 8 animals for the diapause and reactivation group, respectively. A total of 154 and 118 oocytes were fixed and stained for nuclear status after IVM for the two evaluated periods, respectively. The proportion of oocytes in GVBD and MI stages was significantly higher for the reactivation group (see Figure 3, $p<0.05$ ). No differences were observed in the proportion of GV, Al, TI, MII and degenerated oocytes ( $p>0.05$ ) (see Figure 3). In cattle, no differences have been reported regarding the number of follicle number, of collected oocytes, of the cleavage rates and of blastocyst formation, when ovum pick up has been performed in pregnant and non-pregnant donors [26]. Thus, the lower number in oocytes suitable for IVM and reaching the MII stage might suggest an increased follicular atresia after embryonic reactivation. 


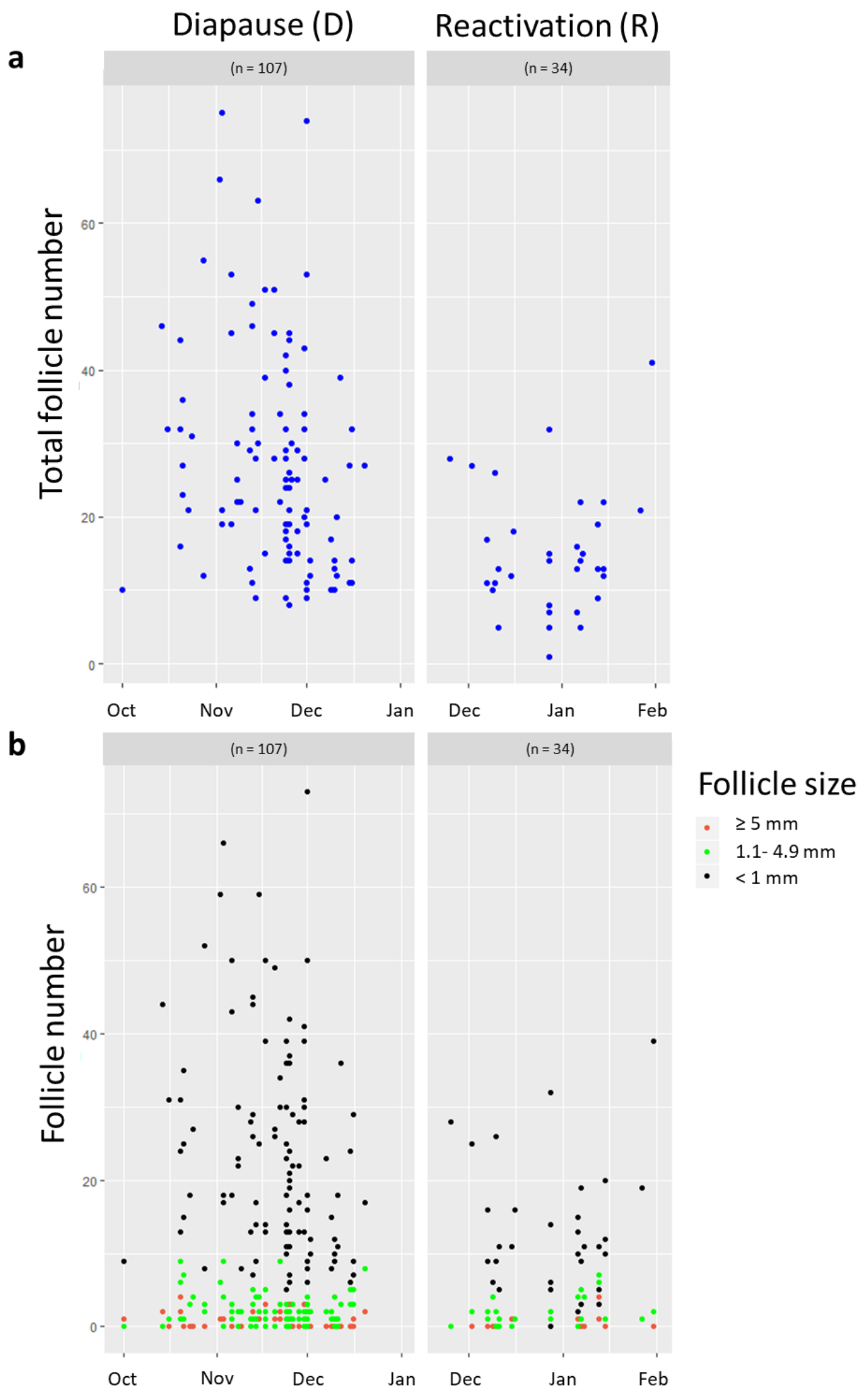

Figure 1. Impact of the embryonic diapause period on the ovarian follicle number in the roe deer. Ovaries were retrieved between October - January. a Total number of antral follicles present during embryonic diapause and reactivation. $b$ Antral follicle number for big: $\geq 5 \mathrm{~mm}$, medium: 1.1-4.9 mm and small: $\leq 1 \mathrm{~mm}$ follicle sizes. Each dot corresponds to one animal, including both ovaries. Data were compared by KruskalWallis test $(p<0.05)$. 


\section{Diapause}
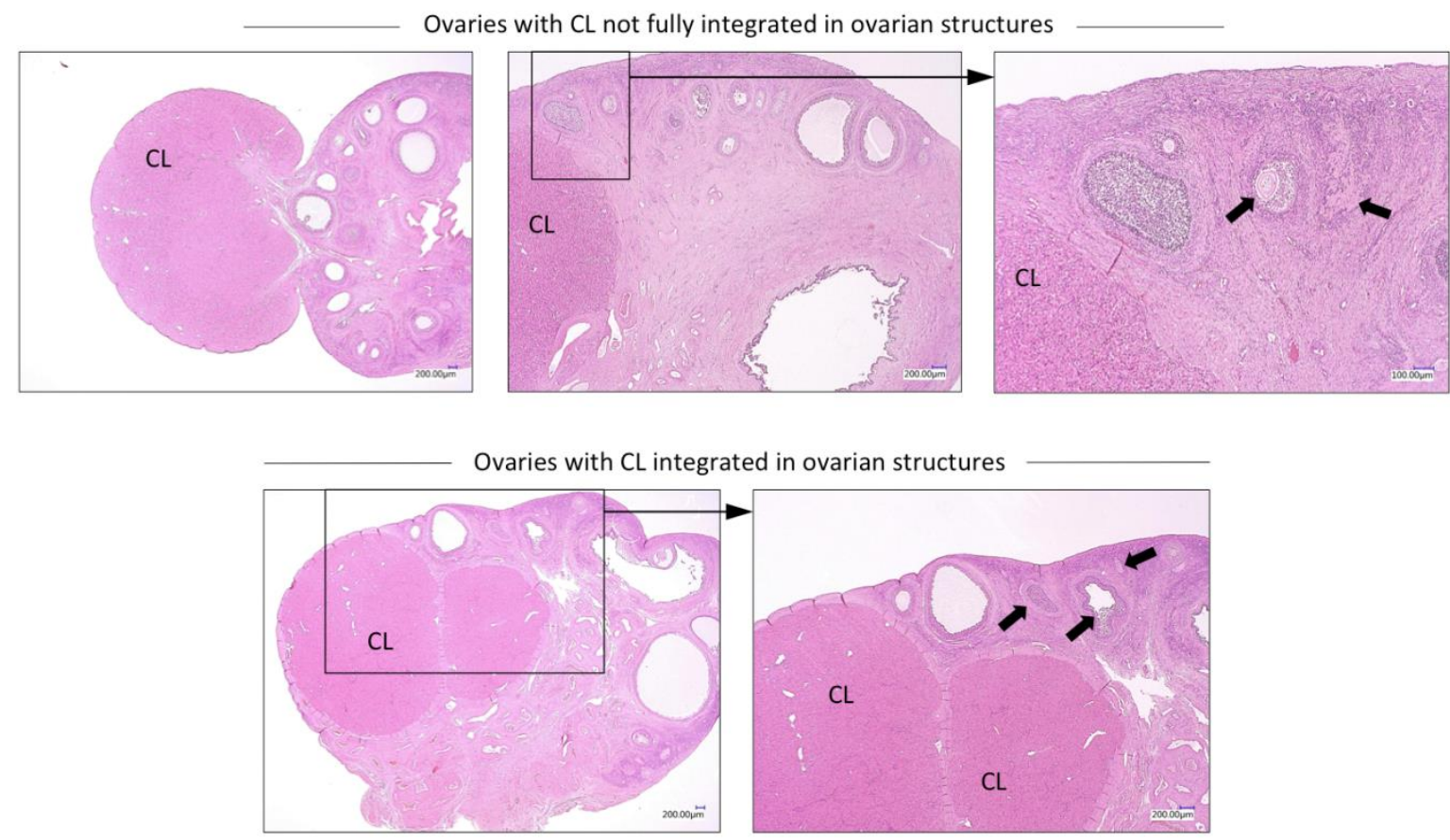

\section{Reactivation}

Ovaries with $\mathrm{CL}$ not fully integrated in ovarian structures
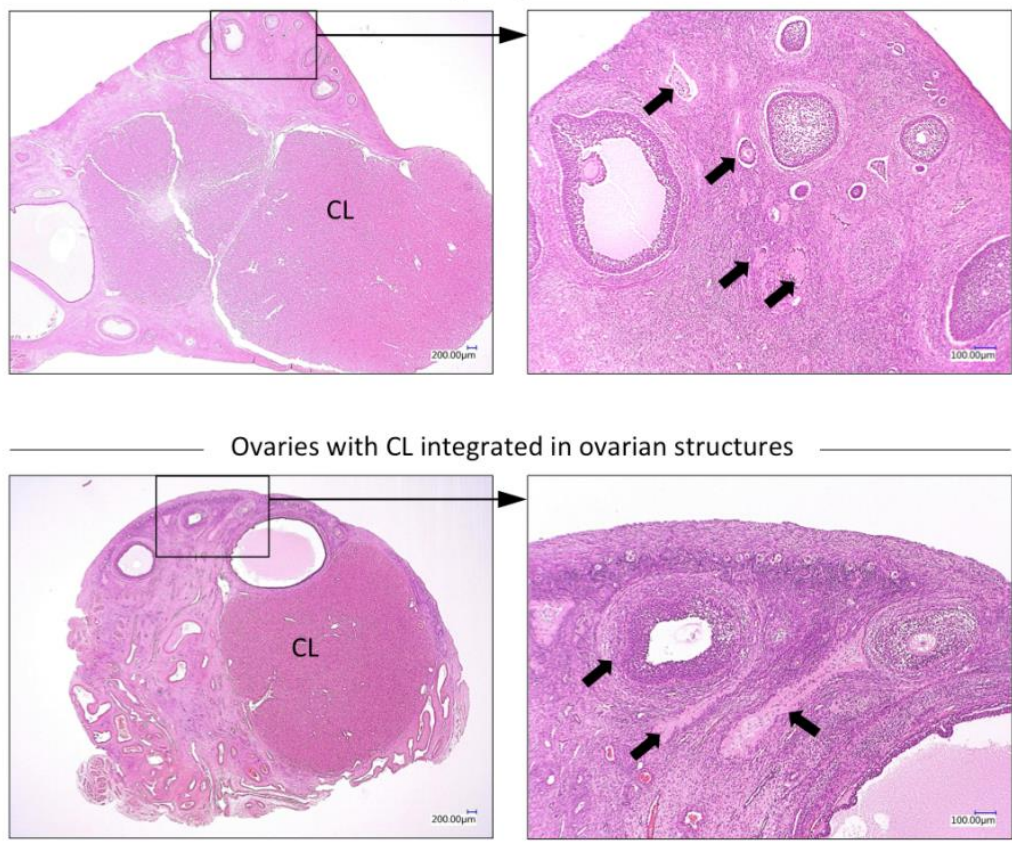

Figure 2. Histological sections of roe deer ovaries during embryonic diapause and after embryonic reactivation. Samples were stained with hematoxylin and eosin. Solid arrows indicate atretic follicles. CL, corpus luteum. 


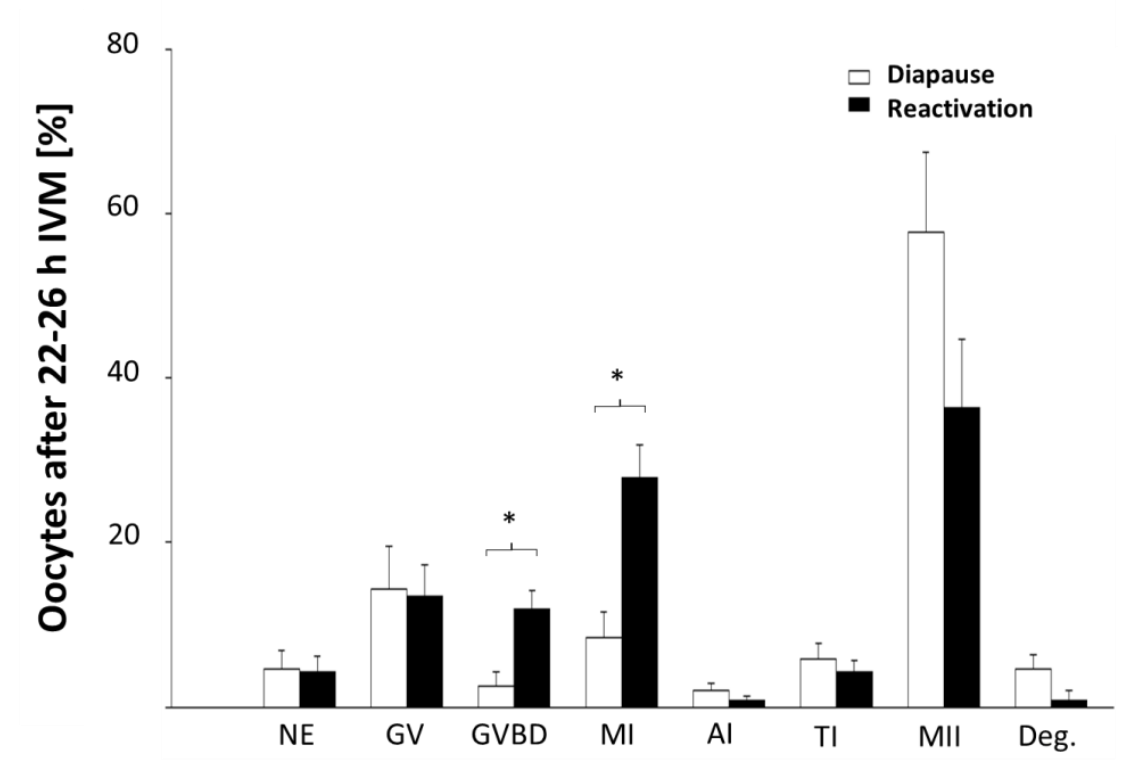

Oocyte developmental stage

Figure 3. Effects of the embryonic developmental stage (determined after embryo retrieval by uterine flushing) on the meiotic resumption capacity of roe deer oocytes. The developmental state was assessed 2226 hours post IVM. Bars represent the percentages calculated using the total number of oocytes per treatment. *Represents statistical significance for the respective meiotic status between treatments $(p<0.05)$. $\mathrm{NE}$, non-evaluable; GV, germinal vesicle stage; GVBD, germinal vesicle breakdown; MI, metaphase I; Al, anaphase I; TI, Telophase I; MII, metaphase II; Deg, Degenerated.

\section{Transcriptome analysis of roe deer oocytes}

We have performed RNA-sequencing on freshly collected GV and in vitro matured oocytes (MII). A total of 220.2 million raw reads were obtained from the eight libraries. Low-quality reads and PCR duplicates were removed and a total of 72.8 million clean reads (20.6 million for GV diapause, 19.4 million for GV reactivation, 16.0 million for MII diapause and 16.7 million for MII reactivation) were further processed for the analyses. A total of 7995 genes were identified and annotated.

Additionally, 4997 and 4868 transcripts for GV and MII oocytes were identified but could not be annotated and were not included for further analyses, limiting the current results. Most of the identified genes (6239, $78 \%$ ) were detected in both GV and MII oocytes. Moreover, some genes were only present in GV (778, $9.7 \%)$ or MII $(397,4.9 \%)$ oocytes (see Figure 4). The results from MII oocytes might not completely resemble the portrait of in vivo matured oocytes, because it has been demonstrated that the expression pattern in these two types of oocytes can differ [31].

The unsupervised clustering of the samples by multiple dimension scaling (MDS) analysis showed a tight grouping according to the oocyte stage and the embryo developmental period (Figure 5). For the dimension 1, an evident separation of the GV oocyte from MII oocytes was observed. The dimension 2 displayed the separation of the oocyte samples according to the diapause and reactivation period (see Figure 5). Additionally, a hierarchical clustering analysis of the differentially expressed genes (DEG) was performed for the four different comparisons (see Figure 6). For oocytes in the GV stage, 18 genes were found to be up-regulated ( $40.9 \%$ of DEG) and 26 downregulated (59.1\%) during diapause (see Figure 6a). For MII oocytes, 14 genes were up-regulated $(43.7 \%)$ and 18 down-regulated (56.2 \%) during diapause (see Figure $6 \mathrm{~b}$ ). When metaphase II oocytes were compared to GV oocytes, 81 (7.9\%) and 220 (12.2\%) genes were up-regulated and $947(92.1 \%)$ and $1 ` 575(87.7 \%)$ were down-regulated during the diapause and reactivation periods, 
respectively (Figure 6c-d, and Bernal Supplementary Tables 1 and 2 https://www.diapause2019.ethz.ch/abstract-submission/).
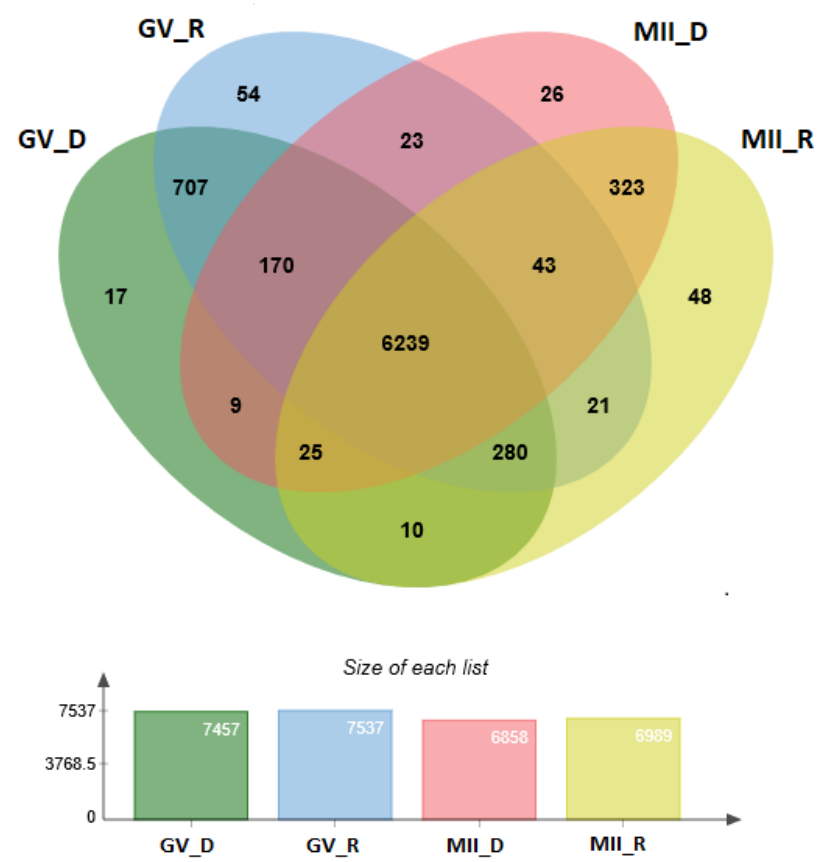

Figure 4. Venn diagram displaying the overlaps of detectable genes. GV, Germinal vesicle; MII, metaphase II; $D$, diapause; $R$, reactivation

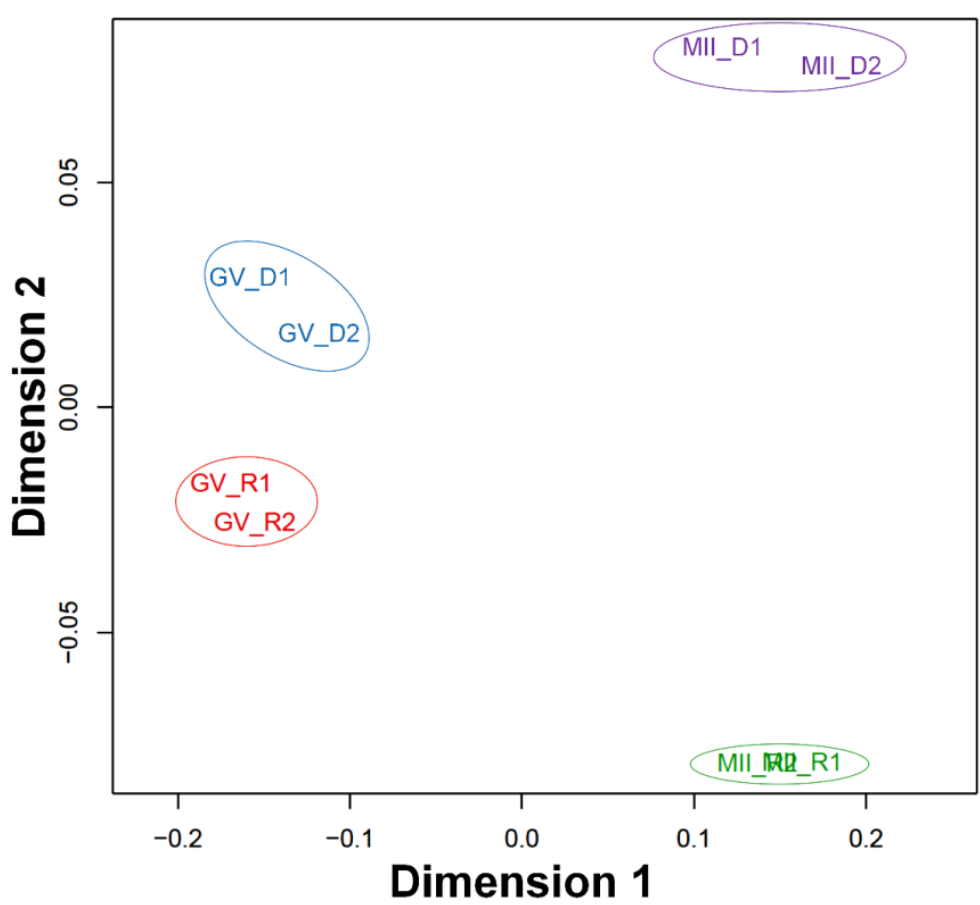

Figure 5. Multidimensional scaling plot for all identified transcripts based on pairwise fold changes between samples. GV, germinal vesicle; MII, metaphase II; D, diapause; R, reactivation; 1 , sample 1; 2, sample 2 . 


\section{Differentially expressed transcripts in immature and mature oocytes}

The potential effects of the embryonic stage ( $D$ vs R) on the oocyte transcriptome were evaluated. Only few genes were found to be differentially expressed in GV and MII oocytes between the two evaluated embryonic periods (GV: 44, MII: 32) (see Figure 7, Table 2-3). From the total number of DEG, more than 700 genes were present in more than one of the evaluated comparisons (overlapping sector of the Venn diagram) (see Figure 7). However, an important number of DEG were found to be only present in the non-overlapping sector of the Venn diagram for each comparison (see Figure 7). When the oocyte profiles after maturation were evaluated against GV oocytes, a lower number of DEG in MIl oocytes from the diapause group (GV_D_vs_MII_D) was observed ( $1^{`} 028$ and $1^{\prime} 795$ for $D$ and $R$, respectively). As the culture conditions were identical for both groups of oocytes, the observed changes are most likely a result of intrinsic anomalies of the oocytes, probably due to the embryonic developmental stage and not due to the maturation system. However, the effects of hormonal profiles, seasonality or time of conception cannot be excluded. Oocytes at the germinal vesicle stage are transcriptionally active and can replace degraded transcripts [32]. Nevertheless, during maturation, oocytes undergo selective degradation of transcripts [33] and MII oocytes become quiescent, while they remain able to use the stored transcripts for protein synthesis. This transcriptional activity pattern could cover-up early or increased consumption of some transcripts, which might be only detectable after the oocyte reaches the MII stage. An increased number of DEG in MII relative to GV oocytes has likewise been reported in oocytes from advanced-age women related to younger-age women, which was a result of a stress-induced usage of transcripts in the aged oocytes [34]. This might indicate that roe deer oocytes after embryonic reactivation experience additional cellular stress, comparable to agingrelated processes. This hypothesis needs further analyses for validation. 
a

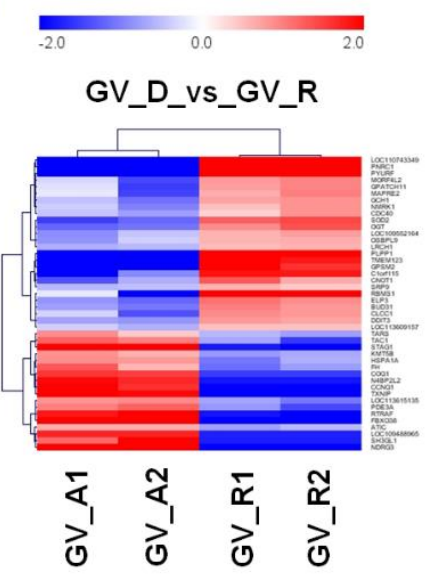

b

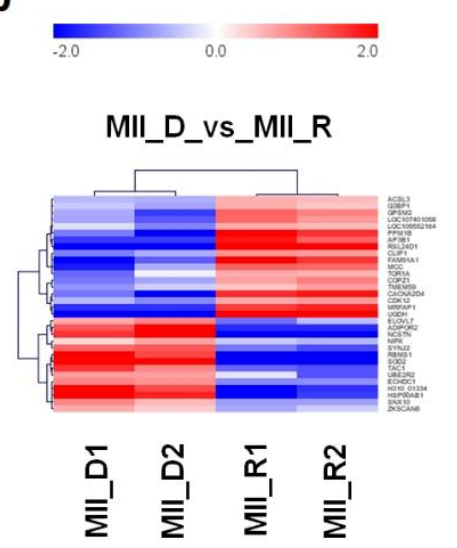

C
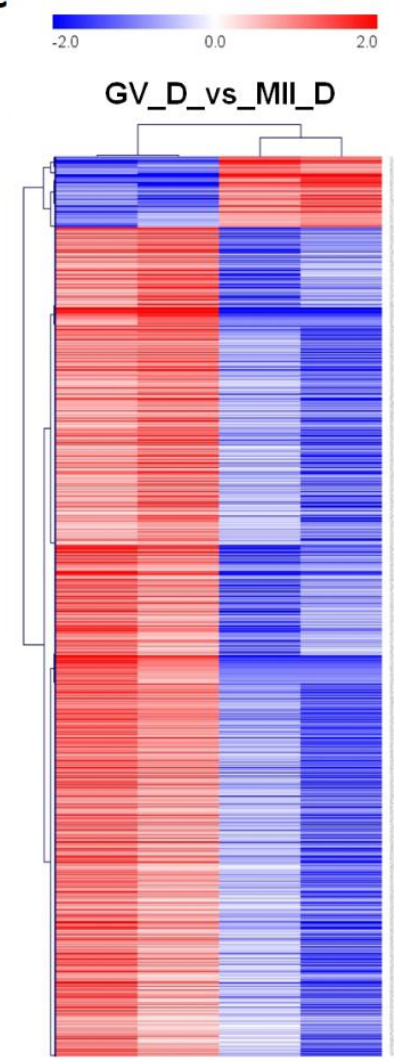

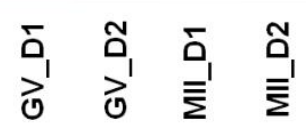

d
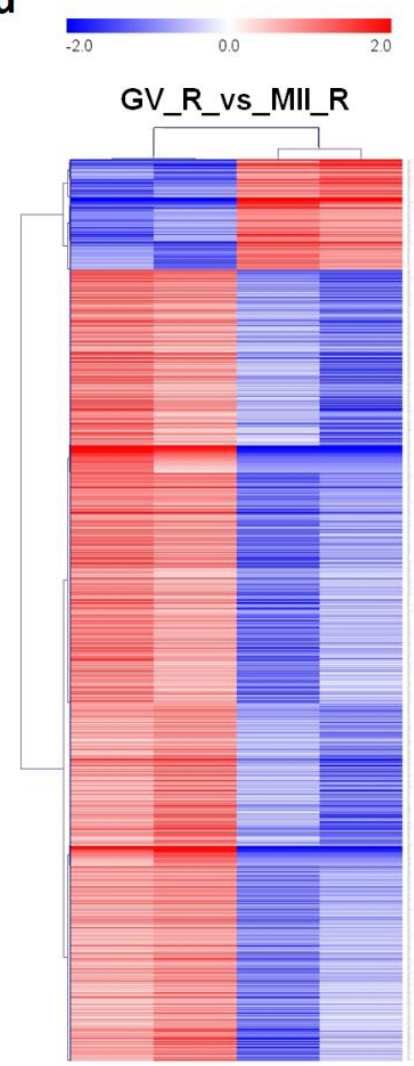

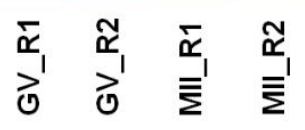

Figure 6. Hierarchical clustering analysis of differentially expressed genes for (a) Germinal vesicle oocytes (GV), (b) Metaphase II oocytes (MII), (c) GV versus MII oocytes during diapause, (d) GV versus MII oocytes during reactivation. Mean-centered expression values (log2 counts per million of sample - mean of $\log 2$ counts per million of all samples). Adjusted p-value $<0.01$ and $>1 \log 2 \mathrm{FC}$. Colour scale from -2 (blue, lower than the mean) to 2 (red, higher than the mean). Each row corresponds to one gene and each column to one sample. D, diapause; R, reactivation; 1 , sample 1; 2, sample 2

Some of the identified DEG in GV and MII oocytes during diapause were related to cell cycle, oxidative stress, metabolism and apoptosis. A selection of up-regulated DEG in GV and/or MII included important signalling-related genes such as the $\mathrm{N}$-myc downstream-regulated gene 3 (NDRG3), involved in cell proliferation, apoptosis and differentiation and up-regulated in malignant tumours [35]. Furthermore, Nicastrin (NCSTN) as a crucial component of the $\gamma$-secretase (GS) enzyme, plays a role in developmental signalling via the transcription factor Notch. Its expression has been involved in propagation and invasion of tumours [36]. SOD2 [37] and TXNIP [38] are modulators of cellular redox signalling protecting the cells from oxidative stress. The adiponectin receptor 2 (ADIPOR2) has been found to be down-regulated in GV oocytes of 32-week-old mice (aged) [39]. The activation of PDE3A, an oocyte specific phosphodiesterase, which remains inactive during the oocyte arrest at the prophase I, leads to a drop in intra-oocyte cAMP levels and meiotic resumption [40] (see Table 2-3).

Among the down-regulated DEG were UDP-glucose 6-dehydrogenase (UGDH), Morf4 family associated protein 1 (MRFAP1), protein phosphatase Mg2+/Mn2+ dependent 1B (PPM1B), transmembrane protein 59 (TMEM59) and cyclin dependent kinase 12 (CDK12). UGDH is involved in signal transduction, cell migration, and cancer growth and metastasis and has been reported to be down-regulated in slowed tumour cell metabolism [41]. Additionally, overexpression of MRFAP1 has resulted in decreased cell growth and increased mitotic apoptosis in HeLa cells [42]. The PPM1B 

219

catalyses the dephosphorylation of a selection of proteins. Its overexpression causes cell-growth arrest or cell death [43]. The overexpression of TMEM59, has been found to stimulate apoptosis in glioma cells [44]. Downregulation of CDK12 has been observed in diapause like-stage with slowed aging in Drosophila melanogaster [45].

Altogether, the expression patterns of the DEG in both GV and MII oocytes match a profile of decreased apoptosis, reduced oxidative stress, higher oocyte survival and slowed aging during embryonic diapause. This suggests a role of this developmental stage on oocyte quality (see Table 2-3).

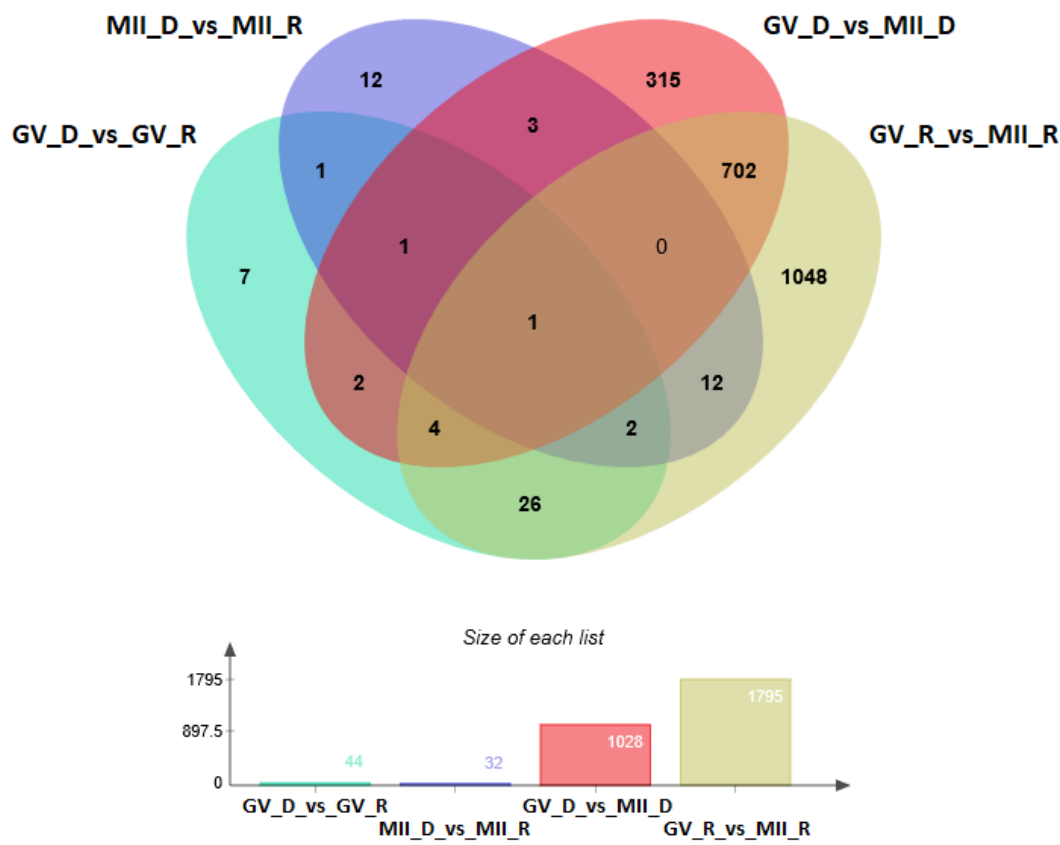

Figure 7. Venn diagram displaying the overlaps of differentially expressed genes. GV, germinal vesicle; MII, metaphase II; D, diapause; $R$, reactivation

Table 2. List of differentially expressed genes (DEG) in GV roe deer oocytes during embryonic diapause related to after embryo reactivation

\begin{tabular}{llcc}
\hline Gene symbol & Gene description & $\begin{array}{l}\text { Log2 fold } \\
\text { change* }\end{array}$ & adj.pvalue \\
\hline LOC110743349 & Uncharacterized & -10.33 & $1.8 \mathrm{E}-19$ \\
PNRC1 & proline rich nuclear receptor coactivator 1 & -7.19 & $2.8 \mathrm{E}-16$ \\
PLPP1 & phospholipid phosphatase 1 & -7.15 & $1.5 \mathrm{E}-11$ \\
PYURF & PIGY upstream reading frame & -6.89 & $2.5 \mathrm{E}-15$ \\
TMEM123 & transmembrane protein 123 & -6.20 & $1.3 \mathrm{E}-06$ \\
GPSM2 & G protein signalling modulator 2 & $6.6 \mathrm{E}-05$ \\
RBMS1 & RNA binding motif single stranded interacting protein 1 & -6.04 & $4.6 \mathrm{E}-04$ \\
C1Orf115 & chromosome 1 open reading frame 115 & -4.09 & $1.5 \mathrm{E}-04$ \\
SOD2 & superoxide dismutase 2 & -3.46 & $5.9 \mathrm{E}-10$ \\
OGT & O-linked N-acetylglucosamine (GlcNAc) transferase & -2.71 & $6.4 \mathrm{E}-03$ \\
CNOT1 & CCR4-NOT transcription complex subunit 1 & -2.24 & $4.0 \mathrm{E}-04$
\end{tabular}


220

\begin{tabular}{|c|c|c|c|}
\hline ELP3 & elongator acetyltransferase complex subunit 3 & -2.01 & 4.0E-03 \\
\hline BUD31 & BUD31 homolog & -1.83 & $1.1 \mathrm{E}-04$ \\
\hline MORF4L2 & mortality factor 4 like 2 & -1.79 & $2.3 \mathrm{E}-06$ \\
\hline GPATCH11 & G-patch domain containing 11 & -1.75 & $1.1 \mathrm{E}-05$ \\
\hline CLCC1 & chloride channel CLIC like 1 & -1.75 & $2.4 \mathrm{E}-07$ \\
\hline MAPRE2 & microtubule associated protein RP/EB family member 2 & -1.67 & $1.8 \mathrm{E}-03$ \\
\hline GCH1 & GTP cyclohydrolase 1 & -1.61 & $5.6 \mathrm{E}-05$ \\
\hline DDIT3 & DNA damage inducible transcript 3 & -1.56 & $6.8 \mathrm{E}-08$ \\
\hline NMRK1 & nicotinamide riboside kinase 1 & -1.39 & $1.4 \mathrm{E}-03$ \\
\hline LOC109552164 & Uncharacterized & -1.38 & $6.7 \mathrm{E}-08$ \\
\hline OSBPL9 & oxysterol binding protein like 9 & -1.25 & $6.5 \mathrm{E}-03$ \\
\hline CDC4O & cell division cycle 40 & -1.21 & $5.1 \mathrm{E}-03$ \\
\hline$L R C H 1$ & leucine rich repeats and calponin homology domain containing 1 & -1.17 & 3.6E-03 \\
\hline SRPg & signal recognition particle 9 & -1.05 & 2.4E-03 \\
\hline LOC113609157 & Uncharacterized & -1.01 & $5.0 \mathrm{E}-08$ \\
\hline ATIC & $\begin{array}{l}\text { 5-aminoimidazole-4-carboxamide ribonucleotide formyltransferase/IMP } \\
\text { cyclohydrolase }\end{array}$ & 1.25 & 3.6E-08 \\
\hline TARS & threonyl-tRNA synthetase & 1.27 & $1.3 \mathrm{E}-03$ \\
\hline KMT5B & lysine methyltransferase 5B & 1.41 & 2.0E-07 \\
\hline HSPA1A & heat shock protein family $A(H s p 70)$ member $1 A$ & 1.64 & $4.9 \mathrm{E}-04$ \\
\hline LOC113615135 & Uncharacterized & 1.73 & $3.5 \mathrm{E}-16$ \\
\hline $\mathrm{FH}$ & fumarate hydratase & 1.85 & $1.8 \mathrm{E}-03$ \\
\hline TAC1 & tachykinin precursor 1 & 2.19 & $1.6 \mathrm{E}-08$ \\
\hline$P D E 3 A$ & phosphodiesterase $3 \mathrm{~A}$ & 2.21 & $9.8 \mathrm{E}-11$ \\
\hline RTRAF & RNA transcription, translation and transport factor & 3.68 & $1.0 \mathrm{E}-08$ \\
\hline FBXO38 & F-box protein 38 & 5.00 & $1.6 \mathrm{E}-04$ \\
\hline COG1 & component of oligomeric golgi complex 1 & 5.12 & 2.4E-04 \\
\hline LOC109488965 & Uncharacterized & 5.52 & $9.8 \mathrm{E}-06$ \\
\hline SH3GL1 & SH3 domain containing GRB2 like 1, endophilin A2 & 5.54 & 7.1E-03 \\
\hline$N 4 B P 2 L 2$ & NEDD4 binding protein 2 like 2 & 5.66 & $2.3 \mathrm{E}-06$ \\
\hline CCNG1 & cyclin G1 & 6.00 & $1.4 \mathrm{E}-05$ \\
\hline STAG1 & stromal antigen 1 & 6.07 & $1.1 \mathrm{E}-07$ \\
\hline TXNIP & thioredoxin interacting protein & 7.05 & $9.8 \mathrm{E}-06$ \\
\hline NDRG3 & NDRG family member 3 & 9.29 & $1.6 \mathrm{E}-40$ \\
\hline
\end{tabular}

* A negative log2 fold change indicates higher expression at reactivation, while a positive log2 fold change indicates higher expression at diapause 
221

Table 3. List of differentially expressed genes in MII roe deer oocytes during embryonic diapause related to reactivation

\begin{tabular}{|c|c|c|c|}
\hline Gene symbol & Gene description & $\begin{array}{l}\text { Log2 fold } \\
\text { change * }\end{array}$ & adj.pvalue \\
\hline$R S L 24 D 1$ & ribosomal L24 domain containing 1 & -7.58 & $3.6 \mathrm{E}-15$ \\
\hline$U G D H$ & UDP-glucose 6-dehydrogenase & -7.06 & $5.9 \mathrm{E}-14$ \\
\hline MRFAP1 & Morf4 family associated protein 1 & -4.88 & $1.3 \mathrm{E}-03$ \\
\hline$A P 3 B 1$ & adaptor-related protein complex 3 , beta 1 subunit & -4.70 & $5.5 \mathrm{E}-03$ \\
\hline PPM1B & protein phosphatase, $\mathrm{Mg} 2+/ \mathrm{Mn} 2+$ dependent $1 \mathrm{~B}$ & -4.50 & $5.4 \mathrm{E}-04$ \\
\hline CACNA2D4 & calcium voltage-gated channel auxiliary subunit alpha2delta 4 & -4.25 & $1.3 \mathrm{E}-03$ \\
\hline FAM91A1 & family with sequence similarity 91 member $A 1$ & -3.25 & $8.5 \mathrm{E}-03$ \\
\hline MCC & MCC regulator of WNT signaling pathway & -2.38 & $1.4 \mathrm{E}-04$ \\
\hline GPSM2 & G protein signalling modulator 2 & -2.15 & $6.9 \mathrm{E}-04$ \\
\hline LOC107401058 & Uncharacterized & -1.95 & $4.8 \mathrm{E}-03$ \\
\hline COPZ1 & coatomer protein complex subunit zeta 1 & -1.74 & $1.6 \mathrm{E}-03$ \\
\hline CLIP1 & CAP-Gly domain containing linker protein 1 & -1.62 & $4.6 \mathrm{E}-08$ \\
\hline CDK12 & cyclin dependent kinase 12 & -1.46 & $8.5 \mathrm{E}-03$ \\
\hline TOR1A & torsin family 1 member $A$ & -1.25 & $7.9 \mathrm{E}-03$ \\
\hline TMEM59 & transmembrane protein 59 & -1.21 & $5.1 \mathrm{E}-04$ \\
\hline LOC109552164 & Uncharacterized & -1.21 & $1.2 \mathrm{E}-06$ \\
\hline ACSL3 & acyl-CoA synthetase long chain family member 3 & -1.14 & $3.2 \mathrm{E}-04$ \\
\hline G3BP1 & G3BP stress granule assembly factor 1 & -1.10 & $3.4 \mathrm{E}-04$ \\
\hline NIFK & nucleolar protein interacting with the FHA domain of MKI67 & 1.03 & $8.5 \mathrm{E}-03$ \\
\hline ZKSCAN8 & zinc finger with KRAB and SCAN domains 8 & 1.06 & 2.1E-03 \\
\hline SNX10 & sorting nexin 10 & 1.51 & $1.2 \mathrm{E}-03$ \\
\hline UBE2R2 & ubiquitin conjugating enzyme E2 R2 & 1.55 & $1.3 \mathrm{E}-03$ \\
\hline ELOVL7 & ELOVL fatty acid elongase 7 & 1.63 & $7.9 \mathrm{E}-03$ \\
\hline$E C H D C 1$ & ethylmalonyl-CoA decarboxylase 1 & 1.81 & $2.8 \mathrm{E}-05$ \\
\hline SYNJ2 & synaptojanin 2 & 2.42 & $2.6 \mathrm{E}-03$ \\
\hline TAC1 & tachykinin precursor 1 & 2.56 & 4.4E-09 \\
\hline H310_01334 & hypothetical protein & 3.94 & $6.9 \mathrm{E}-04$ \\
\hline HSP9OAB1 & heat shock protein 90 alpha family class B member 1 & 4.48 & $4.4 \mathrm{E}-04$ \\
\hline ADIPOR2 & adiponectin receptor 2 & 4.99 & $2.1 \mathrm{E}-03$ \\
\hline SOD2 & superoxide dismutase 2 & 5.63 & 5.7E-06 \\
\hline RBMS1 & RNA binding motif single stranded interacting protein 1 & 5.63 & $2.4 \mathrm{E}-03$ \\
\hline NCSTN & nicastrin & 5.71 & $2.1 \mathrm{E}-04$ \\
\hline
\end{tabular}

* A negative log2 fold change indicates higher expression at reactivation, while a positive log2 fold change indicates higher expression at diapause 


\section{Functional analysis of DEG in GV and MII oocytes and GV versus MII oocytes}

For the GV_D_vs_MII_D and GV_R_vs_MII_R comparisons, an IPA analysis was performed including canonical pathways, functions and upstream regulators. Due to the low number of differentially expressed genes (DEG) for the GV_D_Vs_GV_R and MII_D_Vs_MII_R comparisons, the IPA analysis did not provide statistically significant results.

A function enrichment analysis of DEG in MII oocytes relative to GV oocytes was performed and several categories were overrepresented for the DEG of both developmental stages, such as, "Cellular development, Cellular growth and proliferation", "Cell death and survival", "Cancer", "Cancer, Organismal injury and abnormalities", "DNA replication, recombination, repair", "Protein synthesis", and "Nucleic Acid Metabolism, Small Molecule Biochemistry" (see Table 4). Additionally, "Amino acid metabolism, Post-translational modification, Small molecule biochemistry" and "Molecular transport" were only identified in the diapause group. "Cellular function and maintenance", "Cellular assembly and Organization", "Cell cycle, DNA replication, recombination, and repair", "Carbohydrate Metabolism", "Energy production, Nucleic acid Metabolism, Small molecule biochemistry", and "Gene expression, Protein synthesis" were only enriched at reactivation (see Table 4).

We further analysed the pathway enrichment in MII oocytes compared to GV oocytes. From a total of 39 enriched canonical pathways that were identified (see Table 5), 26 showed a similar inhibition pattern between the diapause and reactivation groups, including "Oxidative phosphorylation", known as one the major pathways for ATP production and also related to the transcript selective degradation process during oocyte maturation in other species [33]. A total of 11 additional canonical pathways that appeared as inhibited were only enriched in the reactivation period and two were only enriched in MII oocyte from the diapause period. The observed increase in number of DEG in the GV_R_vs_MII_R comparison was also reflected in the enrichment of additional functions and pathways. It is known that mitochondria play a crucial role to provide the ATP required for oocyte maturation. In addition, they contain anti-apoptotic and apoptogenic components, which have been related to abnormal activation or fragmentation in aged oocytes (reviewed by [46]). "Function of mitochondria", "Formation of cytoskeleton", "Synthesis of ATP", and "Development of mitochondria" were some of the functions additionally found inhibited or decreased in the oocytes from the reactivation group, suggesting a possible dysfunction of mitochondria in these oocytes. Furthermore, "Homologous recombination" and "Repair of DNA" functions were also found in these oocytes, which might implicate altered meiosis. Two additional depleted pathways in the GV_R_vs_MII_R group ("Cysteine biosynthesis" and "Methionine degradation I") are necessary for "Protein synthesis", another dysregulated function. These modifications might be related to the also found "EIF2 Signalling", since they are involved in global protein synthesis and translation of specific stress-associated mRNA transcripts [47]. Although "Cell survival" was decreased in both groups of oocytes (GV_D_vs_MII_D and GV_R_vs_MII_R), "Apoptosis" was increased after embryonic reactivation, leading to speculate that apoptosis could have already started in the follicle, thereby decreasing the oocyte quality and meiotic resumption capacity, as also observed in our study.

Selective degradation of maternal RNA in oocytes is necessary for oocyte to zygote activation and oocyte meiosis to blastomere mitosis transition [48]. The abnormal degradation of determined transcripts might affect oocyte quality and further embryo development [49], which could be the consequence of the observed expression pattern in the oocytes from the reactivation group. 


\begin{tabular}{|c|c|c|c|c|c|}
\hline Function categories & Diseases and Bio Functions & $\begin{array}{l}\text { Z- score } \\
\text { MII vs. GV } \\
\text { reactivation }\end{array}$ & $\begin{array}{l}\text { Z- score } \\
\text { MII vs. GV } \\
\text { diapause }\end{array}$ & $\begin{array}{l}\text { Number of } \\
\text { genes } \\
\text { MII vs. GV } \\
\text { reactivation }\end{array}$ & $\begin{array}{l}\text { Number of } \\
\text { genes } \\
\text { MII vs. GV } \\
\text { diapause }\end{array}$ \\
\hline Cell Death and Survival & Apoptosis & 3.6 & - & 353 & - \\
\hline Cellular Development, Cellular Growth and Proliferation & Cell proliferation of tumour cell lines & -3.6 & -3.4 & 222 & 140 \\
\hline Cell Death and Survival & Cell survival & -7.6 & -4.4 & 200 & 114 \\
\hline Cancer & Cell transformation & -3.0 & -2.7 & 63 & 47 \\
\hline Cellular Function and Maintenance & Cellular homeostasis & -2.6 & - & 203 & - \\
\hline Cancer, Organismal Injury and Abnormalities & Development of malignant tumour & 2.6 & 2.2 & 785 & 483 \\
\hline Cellular Assembly and Organization & Development of mitochondria & -2.1 & - & 10 & - \\
\hline DNA Replication, Recombination, and Repair & Excision repair & -2.8 & -2.2 & 22 & 14 \\
\hline Cellular Assembly and Organization & Formation of cytoskeleton & -4.0 & - & 55 & - \\
\hline Cellular Assembly and Organization, Cellular Function and Maintenance & Function of mitochondria & -2.0 & - & 20 & - \\
\hline Cell Cycle, DNA Replication, Recombination, and Repair & Homologous recombination & -2.6 & - & 19 & - \\
\hline Carbohydrate Metabolism & Metabolism of carbohydrate & -2.3 & - & 90 & - \\
\hline Nucleic Acid Metabolism & Metabolism of nucleic acid component or derivative & -4.0 & - & 66 & - \\
\hline Protein Synthesis & Metabolism of peptide & -2.0 & -2.2 & 32 & 24 \\
\hline Amino Acid Metabolism, Post-Translational Modification, Small Molecule Biochemistry & Phosphorylation of L-serine & - & -2.2 & - & 5 \\
\hline Post-Translational Modification & Phosphorylation of protein & -2.8 & - & 88 & - \\
\hline $\begin{array}{l}\text { Cellular Growth and Proliferation, Connective Tissue Development and Function, Tissue } \\
\text { Development }\end{array}$ & Proliferation of connective tissue cells & -2.3 & - & 79 & - \\
\hline DNA Replication, Recombination, and Repair & Repair of DNA & -3.6 & - & 50 & - \\
\hline Energy Production, Nucleic Acid Metabolism, Small Molecule Biochemistry & Synthesis of ATP & -3.1 & - & 25 & - \\
\hline Nucleic Acid Metabolism, Small Molecule Biochemistry & Synthesis of purine nucleotide & -3.6 & -2.4 & 36 & 22 \\
\hline Gene Expression & Transactivation & -3.0 & - & 77 & - \\
\hline Gene Expression, Protein Synthesis & Translation of RNA & 2.5 & - & 35 & - \\
\hline Molecular Transport & Transport of molecule & - & -3.0 & - & 126 \\
\hline
\end{tabular}


Table 5. Canonical pathways in MII oocytes relative to GV oocytes during embryonic diapause and reactivation

\begin{tabular}{|c|c|c|}
\hline Canonical Pathways & $\begin{array}{l}\text { Z-score MII vs. GV } \\
\text { reactivation }\end{array}$ & $\begin{array}{l}\text { Z-score MII vs } \\
\text { GV diapause }\end{array}$ \\
\hline Acute Myeloid Leukaemia Signalling & -2.1 & - \\
\hline$\alpha$-Adrenergic Signalling & -2.3 & -2.2 \\
\hline Aldosterone Signalling in Epithelial Cells & - & -2.4 \\
\hline BMP signalling pathway & -2.9 & -2.4 \\
\hline CD40 Signalling & -2.5 & -2.5 \\
\hline Cysteine Biosynthesis III (mammalia) & -2.4 & - \\
\hline D-myo-inositol-5-phosphate Metabolism & -2.1 & - \\
\hline EIF2 Signalling & -2.6 & - \\
\hline ErbB Signalling & -2.7 & -2.8 \\
\hline Gluconeogenesis I & -2.4 & - \\
\hline Glycolysis I & -2.4 & - \\
\hline Fatty Acid $\beta$-oxidation I & -2.5 & -2.0 \\
\hline Ga12/13 Signalling & -3.0 & -2.5 \\
\hline IL-1 Signalling & -3.2 & -2.8 \\
\hline Ketolysis & -2.0 & - \\
\hline IL-6 Signalling & -3.1 & -3.6 \\
\hline iNOS Signalling & -2.0 & -2.4 \\
\hline LPS-stimulated MAPK Signalling & -3.1 & -3.2 \\
\hline Methionine Degradation I (to Homocysteine) & -2.4 & - \\
\hline Melatonin Signalling & -2.9 & -2.4 \\
\hline NGF Signalling & -3.1 & -2.8 \\
\hline NRF2-mediated Oxidative Stress Response & -3.7 & -3.2 \\
\hline Oxidative Phosphorylation & -4.7 & -3.0 \\
\hline PFKFB4 Signalling Pathway & -3.3 & -2.4 \\
\hline 3-phosphoinositide Degradation & -2.5 & - \\
\hline PI3K Signalling in B Lymphocytes & -2.8 & -2.6 \\
\hline PPAR Signalling & 2.1 & 2.5 \\
\hline Pyridoxal 5'-phosphate Salvage Pathway & -2.3 & -2.3 \\
\hline \multicolumn{3}{|l|}{ Pyrimidine Ribonucleotides De Novo } \\
\hline Biosynthesis & -3.0 & -2.0 \\
\hline Rac Signalling & -3.5 & -2.8 \\
\hline
\end{tabular}




$\begin{array}{lcc}\text { Regulation of elF4 and p70S6K Signalling } & -2.1 & -2.0 \\ \text { Pyrimidine Ribonucleotides Interconversion } & -2.8 & - \\ \text { Salvage Pathways of Pyrimidine } & -3.0 & -2.7 \\ \text { Ribonucleotides } & -2.5 & -3.3 \\ \text { STAT3 Pathway } & - & -2.4 \\ \text { Superpathway of Cholesterol Biosynthesis } & -2.6 & -2.0 \\ \text { Superpathway of Methionine Degradation } & -2.5 & -2.3 \\ \text { TGF- } \beta \text { Signalling } & -2.4 & - \\ \text { TCA Cycle II (Eukaryotic) } & -2.0 & -2.0 \\ \text { Tryptophan Degradation III (Eukaryotic) } & \end{array}$

\section{Conclusions}

The present study provides novel insights into ovarian and oocyte physiology in the roe deer. We have observed that ovarian antral follicle number decreased after embryonic reactivation had occurred. Thus, reactivation might be associated with reduced oocyte quality, reflected by the lower number of oocytes suitable for IVM and oocytes capable to reach the MII stage. A deeper view to the oocyte quality as seen from RNA-Seq data revealed differential gene expression between oocytes retrieved during embryonic diapause and after reactivation. The findings could potentially be related to extended lifespan and diminished senescence of the oocyte during embryonic diapause and alleviation of cellular stress after meiotic resumption (see Figure 8 ). For the interpretation of the present results caution is needed. Since does exhibit high fertility rates, sampling of confirmed non-pregnant animals is not possible under hunting conditions. Therefore, seasonality effects cannot be excluded. Furthermore, the follicle counts were performed visually, which might lead to underestimation of the exact number and size of present antral follicles. Additionally, the time between fertilization and sample collection cannot be estimated, adding high variability to the sampling process. A validation of the discovered effects together with further analyses might provide novel quality markers. 


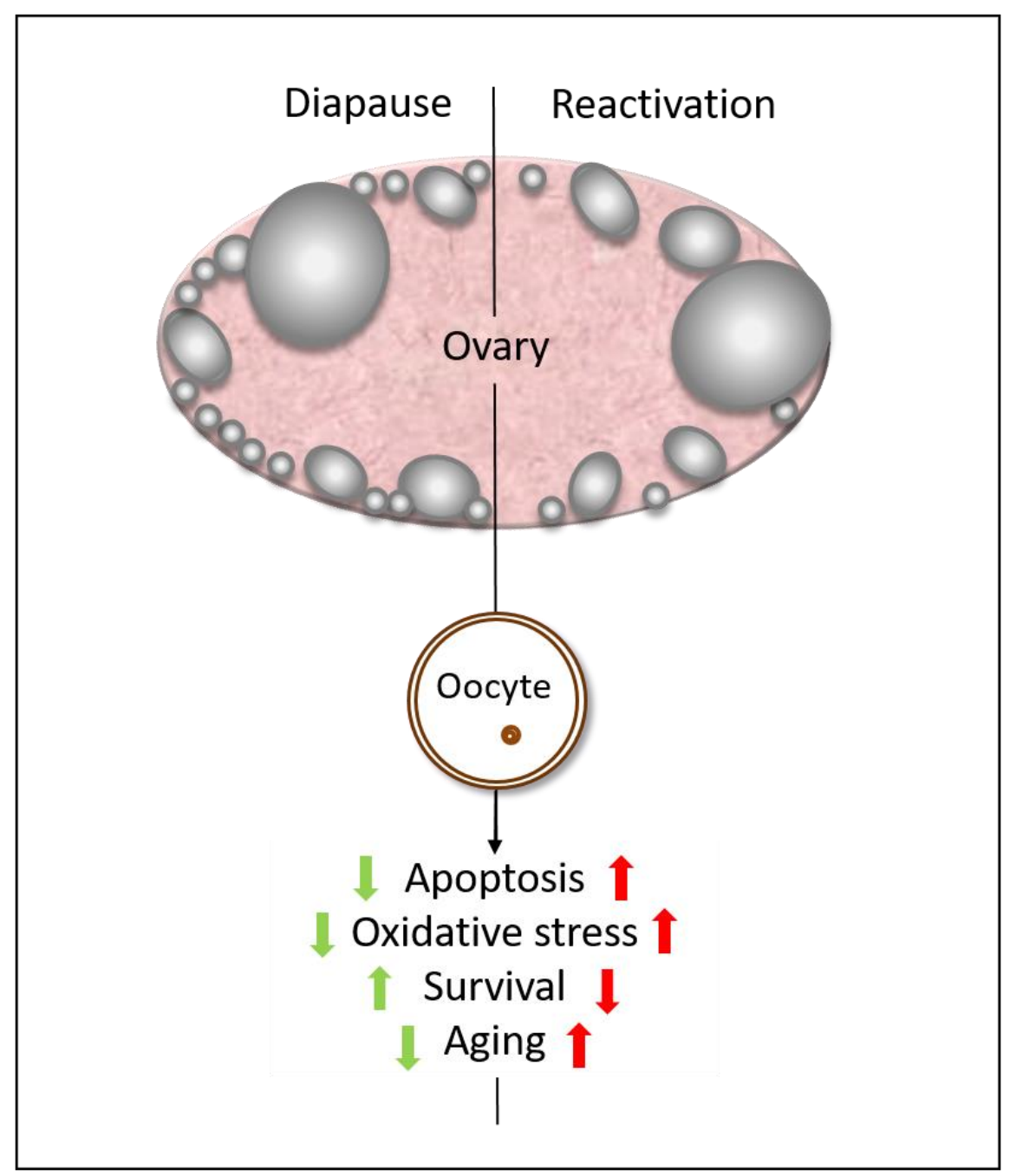

Figure 8. Potential mechanisms of the embryonic diapause and reactivation periods on the antral follicular count and oocyte quality.

\section{Declaration of interest}

The authors declare that there is no conflict of interest that could be perceived as prejudicing the impartiality of the research reported.

\section{Funding}

This study was funded by the Swiss National Science Foundation SNSF (31003A_159734 and 310030_185026).

\section{Acknowledgements}

The authors thank the local hunters in Switzerland and Southern Germany and all people involved in the sampling process for the help in the development of this project. The authors are active participants of the COST Action CA16119 (CellFit In vitro 3D total cell guidance and fitness). 


\section{References}

[1] Fenelon JC, Banerjee A and Murphy BD. 2014 Embryonic diapause: development on hold. The International Journal of Developmental Biology 58(2-4) 163-74.

[2] Renfree MB and Fenelon JC. 2017 The enigma of embryonic diapause. Development 144(18) 3199-

210.

[3] Flint AP, Krzywinski A, Sempere AJ, Mauget R and Lacroix A. 1994 Luteal oxytocin and monoestry in the roe deer Capreolus capreolus. Journal of Reproduction and Fertility 101(3) 651-6.

[4] Strandgaard H. 1972 The Roe Deer (Capreolus capreolus): population at Kalø and the factors regulating its size. Danish Review of Game Biology 7 1-205.

[5] Sempéré AJ, Blanvillain C, Mauget R, Lacroix A and Chemineau P. 1995 Effects of melatonin implantation or artificial long days on seasonal ovulatory activity in roe deer (Capreolus capreolus L.). Animal Reproduction Science 38(1) 127-36.

[6] Hoffmann B, Barth D and Karg H. 1978 Progesterone and estrogen levels in peripheral plasma of the pregnant and nonpregnant roe deer (Capreolus capreolus). Biology of Reproduction 19(5) 931-5.

[7] Schams D, Barth D and Karg H. LH, 1980 FSH and progesterone concentrations in peripheral plasma of the female roe deer (Capreolus capreolus) during the rutting season. Journal of Reproduction and Fertility 60(1) 109-14.

[8] Aitken RJ. 1974 Delayed Implantation in Roe deer (Capreolus-capreolus). Journal of Reproduction and Fertility 39225.

[9] Lambert RT, Ashworth CJ, Beattie L, Gebbie FE, Hutchinson JS, Kyle DJ, et al. 2001 Temporal changes in reproductive hormones and conceptus-endometrial interactions during embryonic diapause and reactivation of the blastocyst in European roe deer (Capreolus capreolus). Reproduction 121(6) 863-71.

[10] Guo J, Zhang T, Guo Y, Sun T, Li H, Zhang X, et al. 2018 Oocyte stage-specific effects of MTOR determine granulosa cell fate and oocyte quality in mice. Proceedings of the National Academy of Sciences 115(23) E5326.

[11] Kogasaka Y, Hoshino Y, Hiradate Y, Tanemura K and Sato E. 2013 Distribution and association of mTOR with its cofactors, raptor and rictor, in cumulus cells and oocytes during meiotic maturation in mice. Molecular Reproduction and Development 80(4) 334-48.

[12] Miles JR, McDaneld TG, Wiedmann RT, Cushman RA, Echternkamp SE, Vallet JL, et al. 2012 MicroRNA expression profile in bovine cumulus-oocyte complexes: possible role of let-7 and miR-106a in the development of bovine oocytes. Animal Reproduction Science 130(1-2) 16-26.

[13] Cheng Y, Kim J, Li XX and Hsueh AJ. 2015 Promotion of ovarian follicle growth following mTOR activation: synergistic effects of AKT stimulators. PloS one 10(2) e0117769-e.

[14] Shimamoto S, Nishimura Y, Nagamatsu G, Hamada N, Kita H, Hikabe O, et al. 2019 Hypoxia induces the dormant state in oocytes through expression of Foxo3. Proceedings of the National Academy of Sciences 116(25) 12321.

[15] Liu JP. 2017 Aging mechanisms and intervention targets. Clinical and Experimental Pharmacology \& Physiology 44 Suppl 1 3-8.

[16] Drews B, Rudolf Vegas A, van der Weijden VA, Milojevic V, Hankele AK, Schuler G, et al. 2019 Do ovarian steroid hormones control the resumption of embryonic growth following the period of diapause in roe deer (Capreolus capreolus)? Reproductive Biology 19(2) 149-57.

[17] Balen AH, Laven JS, Tan SL and Dewailly D. 2003 Ultrasound assessment of the polycystic ovary: international consensus definitions. Human Reproduction Update 9(6) 505-14.

[18] Zaraza J, Oropeza A, Velazquez MA, Korsawe K, Herrmann D, Carnwath JW, et al. 2010 Developmental competence and mRNA expression of preimplantation in vitro-produced embryos from prepubertal and postpubertal cattle and their relationship with apoptosis after intraovarian administration of IGF-1. Theriogenology 74(1) 75-89.

[19] Picelli S, Faridani OR, Bjorklund AK, Winberg G, Sagasser S and Sandberg R. 2014 Full-length RNAseq from single cells using Smart-seq2. Nature Protocols 9(1) 171-81. 
[20] Krueger F. 2015 Trim galore - A wrapper tool around Cutadapt and FastQC to consistently apply quality and adapter trimming to FastQ files. www.bioinformatics.babraham.ac.uk/projects/trim_galore/

[21] Patro R, Duggal G and Kingsford C. 2015 Salmon: Accurate, versatile and ultrafast quantification from RNA-seq data using lightweight-alignment. bioRxiv 021592.

[22] Yang W, Rosenstiel P and Schulenburg H. 2019 aFold - using polynomial uncertainty modelling for differential gene expression estimation from RNA sequencing data. BMC Genomics 20(1) 364-.

[23] Bardou P, Mariette J, Escudié F, Djemiel C and Klopp C. 2014 jvenn: an interactive Venn diagram viewer. BMC Bioinformatics 15(1) 293.

[24] R Core Team. 2019 R: A language and environment for statistical computing. Vienna, Austria: R Foundation for Statistical Computing.

[25] Driancourt MA, Thatcher WW, Terqui M and Andrieu D. 1991 Dynamics of ovarian follicular development in cattle during the estrous cycle, early pregnancy and in response to PMSG. Domestic Animal Endocrinology 8(2) 209-21.

[26] Imai K, Tagawa M, Yoshioka H, Matoba S, Narita M, Inaba Y, et al. 2006 The efficiency of embryo production by ovum pick-up and in vitro fertilization in cattle. Journal of Reproduction and Development 52 S19-S29.

[27] Bartlewski PM, Beard AP and Rawlings NC. 2000 Ultrasonographic study of ovarian function during early pregnancy and after parturition in the ewe. Theriogenology 53(3) 673-89.

[28] Asher GW, Scott IC, O'Neill KT, Smith JF, Inskeep EK and Townsend EC. 1997 Ultrasonographic monitoring of antral follicle development in red deer (Cervus elaphus). Journal of Reproduction and Fertility 111(1) 91-9.

[29] Hermes R, Hildebrandt TB, Göritz F, Jewgenow K, Lengwinat T and Hofmann RR. 2000 Ultrasonography of the ovaries and uterus and grey scale analysis of the endometrium during embryonic diapause in European roe deer. Acta Theriologica 45(4) 559-72.

[30] Aitken RJ, Burton J, Hawkins J, Kerr-Wilson R, Short RV and Steven DH. 1973 Histological and ultrastructural changes in the blastocyst and reproductive tract of the roe deer, Capreolus capreolus, during delayed implantation. Journal of Reproduction and Fertility 34(3) 481-93.

[31] Zhao H, Li T, Zhao Y, Tan T, Liu C, Liu Y, et al. 2019 Single-cell transcriptomics of human oocytes: environment-driven metabolic competition and compensatory mechanisms during oocyte maturation. Antioxidants \& Redox Signaling 30(4) 542-59.

[32] Tesařík J, Trávník P, Kopečný V and Kristek F. 1983 Nucleolar transformations in the human oocyte after completion of growth. Gamete Research 8(3) 267-77.

[33] Su YQ, Sugiura K, Woo Y, Wigglesworth K, Kamdar S, Affourtit J, et al. 2007 Selective degradation of transcripts during meiotic maturation of mouse oocytes. Developmental Biology 302(1) 104-17.

[34] Reyes JM, Silva E, Chitwood JL, Schoolcraft WB, Krisher RL and Ross PJ. 2017 Differing molecular response of young and advanced maternal age human oocytes to IVM. Human Reproduction 32(11) 2199208.

[35] Jing J-S, Li H, Wang S-C, Ma J-M, Yu L-Q and Zhou H. 2018 NDRG3 overexpression is associated with a poor prognosis in patients with hepatocellular carcinoma. Bioscience Reports 38(6) BSR20180907.

[36] Lombardo Y, Filipović A, Molyneux G, Periyasamy M, Giamas G, Hu Y, et al. 2012 Nicastrin regulates breast cancer stem cell properties and tumor growth in vitro and in vivo. Proceedings of the National Academy of Sciences 109(41) 16558.

[37] Zelko IN, Mariani TJ and Folz RJ. 2002 Superoxide dismutase multigene family: a comparison of the CuZn-SOD (SOD1), Mn-SOD (SOD2), and EC-SOD (SOD3) gene structures, evolution, and expression. Free Radical Biology and Medicine 33(3) 337-49.

[38] Miligy IM, Gorringe KL, Toss MS, Al-Kawaz AA, Simpson P, Diez-Rodriguez M, et al. 2018 Thioredoxin-interacting protein is an independent risk stratifier for breast ductal carcinoma in situ. Modern Pathology 31(12) 1807-15. 
[39] Zhang T, Xi Q, Wang D, Li J, Wang M, Li D, et al. 2019 Mitochondrial dysfunction and endoplasmic reticulum stress involved in oocyte aging: an analysis using single-cell RNA-sequencing of mouse oocytes. Journal of Ovarian Research 12(1) 53.

[40] Norris RP, Ratzan WJ, Freudzon M, Mehlmann LM, Krall J, Movsesian MA, et al. 2009 Cyclic GMP from the surrounding somatic cells regulates cyclic AMP and meiosis in the mouse oocyte. Development 136(11) 1869-78.

[41] Saad N, Alberio R, Johnson AD, Emes RD, Giles TC, Clarke P, et al. 2018 Cancer reversion with oocyte extracts is mediated by cell cycle arrest and induction of tumour dormancy. Oncotarget 9(22) 16008-27.

[42] Li DZ, Liu SF, Zhu L, Wang YX, Chen YX, Liu J, et al. 2017 FBXW8-dependent degradation of MRFAP1 in anaphase controls mitotic cell death. Oncotarget 8(57) 97178-86.

[43] Ishii N, Homma T, Watanabe R, Kimura N, Ohnishi M, Kobayashi T, et al. 2019 A heterozygous deficiency in protein phosphatase Ppm1b results in an altered ovulation number in mice. Molecular Medicine Reports 19 5353-60.

[44] Xie Y, Li Q, Yang Q, Yang M, Zhang Z, Zhu L, et al. 2014 Overexpression of DCF1 inhibits glioma through destruction of mitochondria and activation of apoptosis pathway. Scientific Reports 43702.

[45] Kučerová L, Kubrak OI, Bengtsson JM, Strnad H, Nylin S, Theopold U, et al. 2016 Slowed aging during reproductive dormancy is reflected in genome-wide transcriptome changes in Drosophila melanogaster. BMC Genomics 17(1) 50.

[46] Tiwari M, Prasad S, Tripathi A, Pandey AN, Ali I, Singh AK, et al. 2015 Apoptosis in mammalian oocytes: a review. Apoptosis 20(8) 1019-25.

[47] Wek RC, Jiang HY and Anthony TG. 2006 Coping with stress: elF2 kinases and translational control. Biochemical Society Transactions 34(Pt 1) 7-11.

[48] Yu C, Ji S-Y, Sha Q-Q, Dang Y, Zhou J-J, Zhang Y-L, et al. 2016 BTG4 is a meiotic cell cycle-coupled maternal-zygotic-transition licensing factor in oocytes. Nature Structural \& Molecular Biology 23387.

[49] Fan H-Y and Sun Q-Y. 2019 Chapter 12 - Oocyte meiotic maturation. In: Leung PCK, Adashi EY, editors. The Ovary (Third Edition): Academic Press; 181-203. 